\title{
Mode of delivery after a previous cesarean birth, and associated maternal and neonatal morbidity
}

\author{
Carmen B. Young MD, Shiliang Liu MB PhD, Giulia M. Muraca MPH, Yasser Sabr MD MHSc, Tracy Pressey MD, \\ Robert M. Liston MB, K.S. Joseph MD PhD; for the Canadian Perinatal Surveillance System
}

Cite as: CMAJ 2018 May 7;190:E556-64. doi: 10.1503/cmaj.170371

\begin{abstract}
BACKGROUND: The mode of delivery for women with a previous cesarean delivery remains contentious. We conducted a study comparing maternal and infant outcomes after attempted vaginal birth after cesarean delivery versus elective repeat cesarean delivery.
\end{abstract}

METHODS: We used data from the Discharge Abstract Database that includes all hospital deliveries in Canada (excluding Quebec). In our analysis, we included singleton deliveries to women between 37 and 43 weeks gestation who had a single prior cesarean delivery between April 2003 and March 2015. The primary outcomes were severe maternal morbidity and mortality, and serious neonatal morbidity and mortality. We used logistic regression to estimate adjusted rate ratios (RRs) and 95\% confidence intervals (Cls).

RESULTS: Absolute rates of severe maternal morbidity and mortality were low but significantly higher after attempted vaginal birth after cesarean delivery compared with elective repeat cesarean delivery (10.7 v. 5.65 per 1000 deliveries, respectively; adjusted RR 1.96, $95 \% \mathrm{Cl} 1.76$ to 2.19 ). Adjusted rate differences in severe maternal morbidity and mortality, and serious neonatal morbidity and mortality were small (5.42 and 7.09 per 1000 deliveries, respectively; number needed to treat 184 and 141 , respectively). The association between vaginal birth after cesarean delivery, and serious neonatal morbidity and mortality showed a temporal worsening (adjusted RR 0.94, 95\% Cl 0.77 to 1.15 in 2003-2005; adjusted RR $2.07,95 \% \mathrm{Cl} 1.83$ to 2.35 in 2012-2014).

INTERPRETATION: Although absolute rates of adverse outcomes are low, attempted vaginal birth after cesarean delivery continues to be associated with higher relative rates of severe morbidity and mortality in mothers and infants. Temporal worsening of infant outcomes after attempted vaginal birth after cesarean delivery highlights the need for greater care in selecting candidates, and more careful monitoring of labour and delivery.
V aginal birth after cesarean delivery is increasingly contentious as rates of cesarean delivery rise and prior cesarean delivery serves as the most common single indication for a cesarean delivery. Planning mode of delivery for women with a previous cesarean delivery is challenging both for the patient and the care provider. An elective repeat cesarean delivery is associated with an increased risk of surgical complications, as well as an increased risk of abnormal placentation in subsequent pregnancies. ${ }^{1-11}$ On the other hand, attempted vaginal birth after cesarean delivery is associated with a higher risk of uterine rupture and other maternal and infant complications. ${ }^{1-11}$ In addition, a substantial proportion of women attempting a vaginal birth after cesarean delivery will require an emergency cesarean delivery, ${ }^{7,10}$ which increases the risk of maternal and infant complications. ${ }^{11}$

Historically, rates of vaginal birth after cesarean delivery in Canada and the United States increased in the 1980s and early 1990s after endorsements by various groups including the Society of Obstetricians and Gynaecologists of Canada, and the
American College of Obstetricians and Gynecologists. ${ }^{12-17}$ However, studies in the mid-1990s, which showed high rates of severe maternal and infant morbidity associated with vaginal birth after cesarean delivery, resulted in cautionary guidelines from the American College of Obstetricians and Gynecologists in 1998 and 1999, and subsequent declines in rates of vaginal birth after cesarean delivery. ${ }^{1,2,18,19}$ The National Institutes of Health Consensus Development Conference Panel summarized the risks and benefits associated with vaginal birth after cesarean delivery in 2010, and in 2013, the American College of Obstetrics and Gynecology stated that most women with 1 previous cesarean delivery could be considered candidates for vaginal birth. ${ }^{9,20}$ Rates of vaginal birth after cesarean delivery have begun to increase again in the US from a low of about $8.4 \%$ of all births in 2008 and 2009 to $11.3 \%$ in $2014 .{ }^{21}$ In British Columbia, Canada, the proportion of women with a previous cesarean delivery who were deemed eligible for vaginal birth after cesarean delivery increased from $75 \%$ in 2010 to $80 \%$ in $2014 .{ }^{22}$ 
It is important to monitor population rates of maternal and infant adverse outcomes after attempted vaginal birth after cesarean delivery because a uterine scar is a strong risk factor for uterine rupture. We conducted a study to assess whether contemporary obstetrical care has improved maternal and infant outcomes after attempted vaginal birth after cesarean delivery.

\section{Methods}

\section{Setting and design}

We conducted a retrospective cohort study, with all hospital deliveries to women in Canada between April 2003 and March 2015 serving as the source population.

\section{Study population}

For the primary analysis, we restricted the study population to women with a parity of 1 , a previous cesarean delivery (ensuring that all women had only 1 previous cesarean delivery) and, in the current pregnancy, a singleton delivery at 37 to 43 weeks gestation. The comparison of interest was between elective repeat cesarean delivery and attempted vaginal birth after cesarean delivery. We also conducted analyses that compared outcomes in women who had an elective repeat cesarean delivery with those in women who had a successful or failed vaginal birth after cesarean delivery to obtain insight into the mechanisms underlying potential differences in outcomes. Definitions of different modes of delivery, and the diagnostic and procedure codes used are provided in Appendix 1, supplementary Table 1, available at www.cmaj.ca/lookup/suppl/doi:10.1503/cmaj.170371/-/DC1.

\section{Data sources}

We obtained data for the study from the Discharge Abstract Database of the Canadian Institute for Health Information. This database, which contains records for about $98 \%$ of all deliveries in Canada (excluding Quebec), is based on information that is routinely abstracted from medical charts by trained personnel using standardized definitions and processes. ${ }^{23}$ The abstracted information includes details regarding maternal and infant characteristics, labour and delivery, and diagnoses and procedures. All diagnoses during the study period were coded using the International Statistical Classification of Diseases and Related Health Problems, 10th revision, Canadian version, whereas procedures were coded using the Canadian Classification of Health Interventions. The validity of the perinatal information in the Discharge Abstract Database has been assessed previously and found to be accurate. ${ }^{24,25}$

\section{Outcomes}

The primary maternal outcome was composite severe maternal morbidity and mortality, which included severe postpartum hemorrhage (i.e., postpartum hemorrhage requiring blood transfusion, cesarean hysterectomy, hysterectomy or procedures to control bleeding such as ligation or embolization of pelvic vessels, and B-lynch suture of the uterus), disseminated intravascular coagulation, cardiac arrest, cardiopulmonary resuscitation, acute myocardial infarction, heart failure, pulmonary edema, cardiac complications from anesthesia, assisted ventilation, adult respiratory distress syndrome, acute or unspecified renal failure, repair of injury to the bladder or urethra and maternal death. ${ }^{26,27}$ We also evaluated a second composite maternal outcome, restricted severe maternal morbidity and mortality, which included the same components except for postpartum hemorrhage requiring blood transfusion (the most common severe morbidity). We also assessed the following maternal outcomes: uterine rupture (including and excluding dehiscence of the uterine scar) and postpartum hemorrhage that required blood transfusion, procedures to control bleeding or hysterectomy.

The primary infant outcome was composite severe neonatal morbidity and mortality, which included neonatal seizures, any assisted ventilation (including assisted ventilation requiring endotracheal intubation or continuous positive airway pressure) and neonatal death. ${ }^{28,29}$ We also evaluated a second composite neonatal outcome that included neonatal death, neonatal seizures and assisted ventilation requiring endotracheal intubation (excluding assisted ventilation requiring continuous positive airway pressure). We also evaluated the following outcomes: neonatal death, assisted ventilation, neonatal seizures and respiratory distress syndrome.

Infant outcomes were evaluated after we restricted the population to infants without congenital anomalies.

\section{Statistical analysis}

The comparisons in maternal and infant outcomes between the groups of interest were quantified using rates, rate ratios (RRs) and $95 \%$ confidence intervals $(\mathrm{Cl})$, with women who had elective repeat cesarean deliveries as the reference group. Logistic models included maternal age, diabetes mellitus, hypertension and labour induction. We calculated adjusted rate differences from the absolute outcome rates for the elective repeat cesarean delivery group and adjusted RRs for attempted vaginal birth after cesarean delivery group, which we used to compute the number needed to treat (NNT). We evaluated temporal changes in maternal and infant effects from attempted vaginal birth after cesarean delivery by comparing adjusted RRs in early and later study periods (2003-2005 v. 2012-2014). We tested modification of the effect of attempted vaginal birth after cesarean delivery (on composite maternal and neonatal morbidity and mortality) by year using interaction terms.

We repeated these analyses for all women who had a previous cesarean delivery (i.e., without restriction by parity). We also conducted post hoc sensitivity analyses in women at 40 weeks gestation or more to address potential misclassification of elective repeat cesarean and attempted vaginal birth after cesarean delivery (because women planning an elective repeat cesarean delivery would have had this procedure before $40 \mathrm{wk}$ ). We used a 2 -sided $p$ value less than 0.05 to guide inference. All analyses were conducted using SAS version 9.2 (SAS Institute).

\section{Ethics approval}

The study was based on anonymized data and conducted under the surveillance mandate of the Public Health Agency of Canada, and ethics approval was not required. 


\section{Results}

The source population included 3047401 women who delivered between 2003 and 2014. There were 197540 women with a parity of 1 and a previous cesarean delivery who had a singleton delivery at 37 to 43 weeks gestation in the current pregnancy. Of these women, $77426(39.2 \%)$ were 30 to 34 years of age, 7026 (3.6\%) had hypertension, $1510(0.8 \%)$ had diabetes mellitus and 7307 (3.7\%) had labour induction (Table 1). Women who had an elective repeat cesarean delivery were older and had slightly higher rates of hypertension and diabetes mellitus than women who delivered after an attempted vaginal birth after cesarean delivery. The attempted vaginal birth after cesarean delivery rate was $32.8 \%$ (7733/23565) in 2003-2004, decreased to $28.2 \%$ (9633/34205) in 2007-2008 and then increased to $31.4 \%$ (11636/37070) in 20132014. Among women who attempted vaginal birth after cesarean delivery, success rates declined from 50.2\% (1689/3368) in 2003 to $47.8 \%$ (2347/4909) in 2008, before increasing to $50.8 \%$ (2987/5878) in 2014 (Appendix 2, supplementary Figure 1A, available at www. cmaj.ca/lookup/suppl/doi:10.1503/cmaj.170371/-/DC1).

Table 2 shows rates of severe maternal morbidity and mortality after elective repeat cesarean delivery and attempted vaginal birth after cesarean delivery in the study population. Women who had an attempted vaginal birth after cesarean delivery had significantly higher rates of uterine rupture, severe postpartum hemorrhage and composite severe maternal morbidity and mor- tality compared to women who had an elective repeat cesarean delivery. The adjusted RR for composite severe maternal morbidity and mortality among women who had an attempted vaginal birth after cesarean delivery was $1.96(95 \% \mathrm{Cl} 1.76$ to 2.19$)$ and 6.41 (95\% Cl 4.84 to 8.50 ) for uterine rupture (not including dehiscence). Analyses stratified by success/failure of the vaginal birth after cesarean delivery attempt showed that women who had a successful vaginal birth after cesarean delivery had significantly lower rates of restricted severe maternal morbidity and mortality (adjusted RR $0.57,95 \% \mathrm{Cl} 0.45$ to 0.73 ), whereas women with a failed vaginal birth after cesarean delivery had substantially higher rates (adjusted RR 2.58, 95\% Cl 2.25 to 2.95).

Rates of severe neonatal morbidity and mortality followed a mostly similar pattern, with rates of composite severe neonatal morbidity and mortality being significantly higher among women who delivered after an attempted vaginal birth after cesarean delivery compared with those delivering by elective repeat cesarean (adjusted RR 1.49, 95\% Cl 1.38 to 1.61 ; Table 3). Rates of neonatal seizures and assisted ventilation were significantly higher, whereas rates of neonatal death were nonsignificantly higher among women who delivered after an attempted vaginal birth after cesarean delivery. However, rates of neonatal respiratory distress syndrome were significantly lower among women delivering after an attempted vaginal birth after cesarean delivery (adjusted RR $0.90,95 \% \mathrm{Cl} 0.86$ to 0.94 ). Women with a successful vaginal birth after cesarean delivery had significantly lower rates

Table 1: Maternal characteristics and mode of delivery*

\begin{tabular}{|c|c|c|c|c|}
\hline Characteristic & $\begin{array}{c}\text { No. }(\%) \text { of participants } \\
\text { with a previous } \\
\text { cesarean delivery } \\
n=197540\end{array}$ & $\begin{array}{c}\text { No. }(\%) \text { of participants } \\
\text { with an elective repeat } \\
\text { cesarean } \\
n=138836\end{array}$ & $\begin{array}{c}\text { No. (\%) of participants } \\
\text { with an attempted VBAC } \\
\qquad n=58704\end{array}$ & $\begin{array}{l}\text { Rate of attempted } \\
\text { VBAC delivery, } \%\end{array}$ \\
\hline \multicolumn{5}{|l|}{ Maternal age, $†$ yr } \\
\hline$<20$ & $1716(0.9)$ & $1084(0.8)$ & $632(1.1)$ & 36.8 \\
\hline $20-24$ & $17075(8.6)$ & $11063(8.0)$ & $6012(10.2)$ & 35.2 \\
\hline $25-29$ & $46936(23.8)$ & $31600(22.8)$ & $15336(26.1)$ & 32.7 \\
\hline $30-34$ & $77426(39.2)$ & $54267(39.1)$ & 23159 (39.5) & 29.9 \\
\hline$\geq 35$ & $54385(27.5)$ & $40821(29.4)$ & $13564(23.1)$ & 24.9 \\
\hline Had hypertension & $7026(3.6)$ & $5001(3.6)$ & $2025(3.4)$ & 28.8 \\
\hline Had diabetes mellitus & $1510(0.8)$ & $1191(0.9)$ & $319(0.5)$ & 21.1 \\
\hline Had labour induction & $7307(3.7)$ & $0(0.00)$ & 7307 (12.5) & 100.0 \\
\hline \multicolumn{5}{|l|}{ Delivery occurred during } \\
\hline $2003-2004$ & 23565 (11.9) & $15832(11.4)$ & $7733(13.2)$ & 32.8 \\
\hline $2005-2006$ & $30764(15.6)$ & $22037(15.9)$ & $8727(14.9)$ & 28.4 \\
\hline $2007-2008$ & $34205(17.3)$ & $24572(17.7)$ & $9633(16.4)$ & 28.2 \\
\hline 2009-2010 & $35713(18.1)$ & $25406(18.3)$ & $10307(17.6)$ & 28.9 \\
\hline 2011-2012 & $36223(18.3)$ & $25555(18.4)$ & $10668(18.2)$ & 29.5 \\
\hline 2013-2014 & $37070(18.8)$ & $25434(18.3)$ & $11636(19.8)$ & 31.4 \\
\hline
\end{tabular}

Note: VBAC = vaginal birth after cesarean.

*Our study was restricted to women with a parity of 1 who had a previous cesarean delivery and who delivered a singleton at 37 to 43 weeks gestation in the current pregnancy in Canada (excluding Quebec) from 2003 to 2014. Participants with missing values were excluded.

†For maternal age, the denominators used were 197538 (no. of participants with a previous cesarean delivery), 138835 (no. of participants with an elective repeat cesarean) and 58703 (no. of participants with an attempted VBAC). 
of neonatal respiratory distress syndrome, whereas those with a failed vaginal birth after cesarean delivery had significantly higher rates. Failed vaginal birth after cesarean delivery was associated with a threefold higher rate of neonatal death (Table 3).
Table 4 provides adjusted rate differences for maternal and infant outcomes and the NNT for attempted vaginal birth after cesarean delivery; 135 women attempting a vaginal birth after cesarean delivery would have to be delivered by elective repeat

Table 2: Severe maternal morbidity and mortality, by type of delivery*

\begin{tabular}{|c|c|c|c|c|}
\hline Outcome & No. of deliveries & Rate per 1000 deliveries & Crude RR $(95 \% \mathrm{CI})$ & Adjusted RR† $(95 \% \mathrm{CI})$ \\
\hline \multicolumn{5}{|l|}{ Uterine rupture } \\
\hline Elective repeat cesarean & 243 & 1.75 & 1.00 (Ref.) & 1.00 (Ref.) \\
\hline Attempted VBAC & 583 & 9.93 & 5.72 (4.92 to 6.65$)$ & 5.24 (4.48 to 6.12$)$ \\
\hline Successful VBAC & 38 & 1.30 & $0.74(0.53$ to 1.04$)$ & $0.64(0.45$ to 0.90$)$ \\
\hline Failed VBAC & 545 & 18.5 & $10.8(9.24$ to 12.5$)$ & 9.62 (8.23 to 11.3 ) \\
\hline \multicolumn{5}{|c|}{ Rupture not including dehiscence } \\
\hline Elective repeat cesarean & 69 & 0.50 & 1.00 (Ref.) & 1.00 (Ref.) \\
\hline Attempted VBAC & 194 & 3.30 & $6.67(5.07$ to 8.78$)$ & 6.41 (4.84 to 8.50$)$ \\
\hline Successful VBAC & 15 & 0.51 & 1.03 (0.59 to 1.80$)$ & 0.94 (0.54 to 1.66$)$ \\
\hline Failed VBAC & 179 & 6.08 & 12.3 (9.32 to 16.2$)$ & $11.6(8.77$ to 15.5$)$ \\
\hline \multicolumn{5}{|c|}{ PPH and blood transfusion } \\
\hline Elective repeat cesarean & 226 & 1.63 & 1.00 (Ref.) & 1.00 (Ref.) \\
\hline Attempted VBAC & 264 & 4.50 & 2.77 (2.32 to 3.31$)$ & 2.80 (2.33 to 3.37$)$ \\
\hline Successful VBAC & 153 & 5.23 & 3.22 (2.63 to 3.96$)$ & 3.34 (2.69 to 4.14$)$ \\
\hline Failed VBAC & 111 & 3.77 & 2.32 (1.85 to 2.91$)$ & 2.32 (1.84 to 2.92 ) \\
\hline \multicolumn{5}{|c|}{ PPH and procedures for bleeding } \\
\hline Elective repeat cesarean & 213 & 1.53 & 1.00 (Ref.) & 1.00 (Ref.) \\
\hline Attempted VBAC & 125 & 2.13 & 1.39 (1.11 to 1.73$)$ & 1.44 (1.15 to 1.82$)$ \\
\hline Successful VBAC & 19 & 0.65 & 0.42 (0.26 to 0.68$)$ & 0.44 (0.28 to 0.72$)$ \\
\hline Failed VBAC & 106 & 3.60 & 2.35 (1.86 to 2.97$)$ & 2.33 (1.83 to 2.97$)$ \\
\hline \multicolumn{5}{|l|}{ PPH and hysterectomy } \\
\hline Elective repeat cesarean & 76 & 0.55 & 1.00 (Ref.) & 1.00 (Ref.) \\
\hline Attempted VBAC & 32 & 0.55 & 1.00 (0.66 to 1.51$)$ & 1.05 (0.68 to 1.62$)$ \\
\hline Successful VBAC & 5 & 0.17 & 0.31 (0.13 to 0.77$)$ & $0.33(0.13$ to 0.84$)$ \\
\hline Failed VBAC & 27 & 0.92 & 1.68 (1.08 to 2.60$)$ & 1.67 (1.06 to 2.64$)$ \\
\hline \multicolumn{5}{|c|}{ Maternal morbidity and mortality $\ddagger$} \\
\hline Elective repeat cesarean & 784 & 5.65 & 1.00 (Ref.) & 1.00 (Ref.) \\
\hline Attempted VBAC & 629 & 10.7 & 1.91 (1.72 to 2.12 ) & 1.96 (1.76 to 2.19$)$ \\
\hline Successful VBAC & 209 & 7.14 & 1.27 (1.09 to 1.48$)$ & 1.32 (1.13 to 1.55$)$ \\
\hline Failed VBAC & 420 & 14.3 & 2.55 (2.26 to 2.87 ) & 2.54 (2.25 to 2.87 ) \\
\hline \multicolumn{5}{|c|}{ Restricted severe morbidity } \\
\hline Elective repeat cesarean & 645 & 4.65 & 1.00 (Ref.) & 1.00 (Ref.) \\
\hline Attempted VBAC & 422 & 7.19 & 1.55 (1.37 to 1.76$)$ & 1.63 (1.43 to 1.85$)$ \\
\hline Successful VBAC & 73 & 2.49 & 0.54 (0.42 to 0.68$)$ & 0.57 (0.45 to 0.73$)$ \\
\hline Failed VBAC & 349 & 11.9 & 2.57 (2.26 to 2.93 ) & 2.58 (2.25 to 2.95 ) \\
\hline
\end{tabular}

Note: $\mathrm{Cl}=$ confidence interval, $\mathrm{PPH}=$ postpartum hemorrhage, $\mathrm{RR}=$ rate ratio, $\mathrm{VBAC}=$ vaginal birth after cesarean.

*There were 138836 elective repeat cesarean deliveries, 58704 attempted VBAC deliveries, 29261 successful VBAC deliveries and 29443 failed VBAC deliveries. Our study was restricted to women with a parity of 1 who had a previous cesarean delivery and who delivered a singleton at 37 to 43 weeks gestation in the current pregnancy in Canada (excluding Quebec) from 2003 to 2014. †Logistic models included maternal age, diabetes mellitus, hypertension and labour induction.

¥Severe maternal morbidity and mortality included death, acute myocardial infarction, heart failure, pulmonary edema, disseminated intravascular coagulation, cardiac arrest, assisted ventilation, cardiac complications from anesthesia, cardiopulmonary resuscitation, adult respiratory distress syndrome, acute/unspecified renal failure, blood transfusion given PPH, shock procedures to control bleeding given PPH, cesarean hysterectomy given PPH, total hysterectomy open approach given PPH, subtotal hysterectomy open approach given PPH and repair of injury to bladder and urethra.

IRestricted severe morbidity included the same conditions as for severe maternal morbidity and mortality, except blood transfusion given PPH. 
cesarean to prevent 1 case of uterine rupture. The NNT was 184 for severe maternal morbidity and mortality, and 141 for severe neonatal morbidity and mortality.

Analyses comparing the association of vaginal birth after cesarean delivery with maternal and infant morbidity and mortality in
2003-2005 versus 2012-2014 showed no significant differences in adjusted RRs for adverse maternal outcomes but did show significantly higher adjusted RRs for severe neonatal morbidity and mortality in the later period (Table 5). Attempted vaginal birth after cesarean delivery was not associated with severe neonatal morbidity and

Table 3: Neonatal death and serious neonatal morbidity, by type of delivery*

$\begin{array}{lll}\text { Outcome } & \text { No. of births } \quad \text { Rate per } 1000 \text { deliveries }\end{array}$

Crude RR $(95 \% \mathrm{CI})$

Adjusted RR† (95\% Cl)

\section{Neonatal death}

No. of births

Elective repeat cesarean

Attempted VBAC

Successful VBAC

Failed VBAC

\section{Assisted ventilation}

Elective repeat cesarean

Attempted VBAC

Successful VBAC

Failed VBAC

\section{Assisted ventilation excluding CPAP}

Elective repeat cesarean

Attempted VBAC

Successful VBAC

Failed VBAC

\section{Neonatal seizures}

Elective repeat cesarean

Attempted VBAC

Successful VBAC

Failed VBAC

\section{Respiratory distress syndrome}

Elective repeat cesarean

Attempted VBAC

Successful VBAC

Failed VBAC

Neonatal mortality and morbidity

Elective repeat cesarean

Attempted VBAC

Successful VBAC

Failed VBAC

\section{Restricted mortality and morbidity 9}

Elective repeat cesarean

Attempted VBAC

Successful VBAC

Failed VBAC
0.08

0.22

$<0.18$

0.29

11

12

$<5$

$\begin{array}{ll}1835 & 14.0 \\ 1111 & 20.0 \\ 400 & 14.3 \\ 711 & 25.6\end{array}$

396

362

118

244

79

77

30

47

7231

2699

1032

1667

1903

1157

420

737

469

415

140

275

60.1

14.5

20.8

15.0

26.6

3.57

7.45

5.01

9.91

1.00 (Ref.)
.58 (1.14 to 5.84$)$
$.71(0.55$ to 8.57$)$
$3.45(1.39$ to 8.57$)$

1.00 (Ref.)

1.44 (1.33 to 1.55 )

1.03 (0.92 to 1.14 )

1.86 (1.70 to 2.03 )

1.00 (Ref.)

2.17 (1.88 to 2.50 )

1.40 (1.14 to 1.73 )

2.94 (2.50 to 3.45 )

1.00 (Ref.)

2.30 (1.68 to 3.15 )

1.79 (1.17 to 2.72 )

2.82 (1.97 to 4.05 )

1.00 (Ref.)

0.88 (0.84 to 0.92 )

0.66 (0.62 to 0.70$)$

1.10 (1.04 to 1.16$)$

$$
1.00 \text { (Ref.) }
$$

1.45 (1.34 to 1.56$)$

1.04 (0.93 to 1.16 )

1.86 (1.71 to 2.03 )

$$
1.00 \text { (Ref.) }
$$

2.10 (1.84 to 2.40 )

1.41 (1.16 to 1.70$)$

2.80 (2.41 to 3.25 )
1.00 (Ref.)

2.32 (0.99 to 5.48 )

1.46 (0.45 to 4.78 )

3.22 (1.26 to 8.24$)$

1.00 (Ref.)

1.49 (1.38 to 1.62 )

1.08 (0.96 to 1.20 )

1.88 (1.72 to 2.06 )

1.00 (Ref.)

2.15 (1.85 to 2.49 )

1.38 (1.12 to 1.71$)$

2.87 (2.44 to 3.39 )

1.00 (Ref.)

2.30 (1.65 to 3.19 )

1.78 (1.15 to 2.76 )

2.77 (1.91 to 4.01 )

1.00 (Ref.)

0.90 ( 0.86 to 0.94 )

0.68 (0.63 to 0.72 )

1.12 (1.06 to 1.18 )

1.00 (Ref.)

1.49 (1.38 to 1.61$)$

1.08 (0.97 to 1.21 )

1.88 (1.72 to 2.05 )

1.00 (Ref.)

2.07 (1.81 to 2.38 )

1.38 (1.13 to 1.68 )

2.73 (2.34 to 3.19 )

Note: $\mathrm{Cl}=$ confidence interval, $\mathrm{CPAP}=$ continuous positive airway pressure, $\mathrm{RR}=$ rate ratio, $\mathrm{VBAC}=$ vaginal birth after cesarean .

*There were 131493 elective repeat cesarean births, 55691 attempted VBAC births, 27947 successful VBAC births and 27744 failed VBAC births without congenital anomalies. Our study was restricted to women with a parity of 1 who had a previous cesarean delivery and who delivered a singleton at 37 to 43 weeks gestation in the current pregnancy in Canada (excluding Quebec) from 2003 to 2014. Births with congenital anomalies were excluded.

tLogistic models included maternal age, diabetes mellitus, hypertension and labour induction.

$\ddagger$ Neonatal mortality and morbidity included neonatal death, neonatal seizures and assisted ventilation including CPAP.

IRestricted mortality and morbidity included neonatal death, neonatal seizures and assisted ventilation not including CPAP. 
Table 4: Adjusted rate differences for maternal and fetal outcomes (per $\mathbf{1 0 0 0}$ deliveries) and number needed to treat for vaginal birth after cesarean delivery, by delivery type*

\section{Adjusted rate difference}

\section{Outcome}

Point estimate $(95 \% \mathrm{Cl})$

NNT

Attempted VBAC delivery $\dagger$

Maternal

Uterine rupture

Uterine rupture not including dehiscence

PPH and blood transfusion

Severe morbidity

Restricted morbidity

Neonatal

Death

Assisted ventilation

Assisted ventilation excluding CPAP

Seizures

Respiratory distress syndrome

Mortality and morbidity

Restricted mortality and morbidity

\section{Successful VBAC $\uparrow$}

Maternal

Uterine rupture

Uterine rupture not including dehiscence

PPH and blood transfusion

Severe morbidity

Restricted morbidity

Neonatal

Assisted ventilation

Respiratory distress syndrome

Mortality and morbidity

\section{After failed VBAC delivery $\dagger$}

Maternal

\begin{tabular}{|c|c|c|}
\hline Uterine rupture & $15.1(12.7$ to 18.0$)$ & 66 \\
\hline Uterine rupture not including dehiscence & 5.27 (3.86 to 7.21$)$ & 190 \\
\hline PPH and blood transfusion & 2.15 (1.37 to 3.13$)$ & 465 \\
\hline Severe morbidity & 8.70 (7.06 to 10.6$)$ & 115 \\
\hline Restricted morbidity & 7.34 (5.81 to 9.06$)$ & 136 \\
\hline \multicolumn{3}{|l|}{ Neonatal } \\
\hline Death & $0.19(0.02$ to 0.61$)$ & 5385 \\
\hline Assisted ventilation & $12.3(10.1$ to 14.8$)$ & 81 \\
\hline Assisted ventilation excluding CPAP & $5.63(4.34$ to 7.20$)$ & 178 \\
\hline Seizures & 1.06 (0.55 to 1.81$)$ & 940 \\
\hline Respiratory distress syndrome & 6.60 (3.30 to 9.90$)$ & 152 \\
\hline Mortality and morbidity & 12.7 (10.4 to 15.2$)$ & 79 \\
\hline Restricted mortality and morbidity & 6.17 (4.78 to 7.81$)$ & 162 \\
\hline
\end{tabular}

mortality in 2003-2005 (adjusted RR 0.94, 95\% Cl 0.77 to 1.15 ), whereas this association was significant in 2012-2014 (adjusted RR 2.07, 95\% Cl 1.83 to $2.35 ; p$ value for difference in rate ratios $<0.05)$. The interaction term between attempted vaginal birth after cesarean delivery and year was significant for the neonatal morbidity outcomes $(p=0.36$ for composite severe maternal morbidity, $p<0.001$ for composite serious neonatal morbidity and $p<0.001$ for respiratory distress syndrome; Appendix 2).

We found that analyses conducted for all women with a previous cesarean delivery showed essentially the same results (Appendix 1 , supplementary Tables 1-6) with slight attenuation in adjusted RRs. Sensitivity analyses that were restricted to women at 40 weeks or more gestation also showed similar results for maternal outcomes (Appendix 1, supplementary Table 7) and significantly larger effects for neonatal outcomes (Appendix 1, supplementary Table 8). The adjusted RR expressing the association between attempted vaginal birth after cesarean delivery and severe neonatal morbidity and mortality, which was 1.49 $(95 \% \mathrm{Cl} 1.38$ to 1.61$)$ in the primary analysis, was 2.37 (95\% Cl 1.91 to 2.96$)$ in this sensitivity analysis (difference in RRs $p<0.05$ ).

\section{Interpretation}

Our study showed that absolute rates of severe maternal and neonatal morbidity and mortality were low among women who attempted a vaginal birth after cesarean delivery and those who had an elective repeat cesarean delivery. However, relative rates of severe maternal and serious neonatal morbidity and mortality were substantially higher following attempted vaginal birth after cesarean delivery. Perhaps the most concerning finding was the temporal change in the effect of attempted vaginal birth after cesarean delivery on infant outcomes: severe neonatal morbidity and mortality rates were not significantly different following an attempted vaginal birth after cesarean delivery in 2003-2005, whereas such morbidity and mortality was 2 -fold higher following an attempted vaginal birth after cesarean delivery in 2012-2014.

Although the number of women with a previous cesarean delivery increased from 2003 to 2014, rates of attempted vaginal birth after cesarean delivery and rates of success after a trial of labour were essentially unchanged. These stable rates likely conceal substantial changes in attitudes toward attempted vaginal birth after 
cesarean delivery over the study period among women who are pregnant and health care providers. In 1998, the American College of Obstetricians and Gynecologists recommended that vaginal birth after cesarean delivery be attempted only in well-equipped hospitals with "ready availability" emergency care. ${ }^{15}$ This ready availability terminology gave way to "immediate availability of emergency care" in $1999 .{ }^{16}$ The subsequent sharp decline in rates of vaginal birth after cesarean delivery led to a moderation of the

\section{Table 5: Maternal and neonatal outcomes for vaginal birth after cesarean delivery for 2003-} 2005 versus 2012-2014, by delivery type*

\begin{tabular}{|c|c|c|}
\hline \multirow[b]{2}{*}{ Outcome } & \multicolumn{2}{|c|}{ Adjusted RR $(95 \% \mathrm{Cl}) \dagger \ddagger$} \\
\hline & 2003-2005 & 2012-2014 \\
\hline \multicolumn{3}{|l|}{ Attempted VBAC } \\
\hline \multicolumn{3}{|l|}{ Maternal } \\
\hline Uterine rupture & 6.74 (4.74 to 9.58$)$ & 5.47 (4.14 to 7.23$)$ \\
\hline Uterine rupture not including dehiscence & 7.01 (3.71 to 13.2$)$ & 9.08 (5.20 to 15.9$)$ \\
\hline Severe morbidity & $1.80(1.32$ to 2.46$)$ & 1.93 (1.62 to 2.30$)$ \\
\hline \multicolumn{3}{|l|}{ Neonatal } \\
\hline Assisted ventilation & 0.91 (0.74 to 1.12$)$ & 2.08 (1.84 to 2.36$)$ \\
\hline Assisted ventilation excluding CPAP & $1.42(0.96$ to 2.10$)$ & $3.11(2.40$ to 4.03$)$ \\
\hline Seizures & 1.62 (0.81 to 3.25$)$ & 2.92 (1.54 to 5.55$)$ \\
\hline Respiratory distress syndrome & 0.81 (0.74 to 0.89$)$ & $1.07(0.98$ to 1.18$)$ \\
\hline Mortality and morbidity & 0.94 (0.77 to 1.15$)$ & 2.07 (1.83 to 2.35$)$ \\
\hline Restricted mortality and morbidity & 1.43 (1.01 to 2.02 ) & 2.97 ( 2.32 to 3.79$)$ \\
\hline \multicolumn{3}{|l|}{ Successful VBAC } \\
\hline \multicolumn{3}{|l|}{ Maternal } \\
\hline Uterine rupture & 0.71 (0.33 to 1.53$)$ & $0.69(0.38$ to 1.25$)$ \\
\hline Uterine rupture not including dehiscence & $0.66(0.15$ to 2.95$)$ & 1.30 (0.47 to 3.59$)$ \\
\hline Severe morbidity & 0.81 (0.47 to 1.39$)$ & 1.15 (0.89 to 1.49$)$ \\
\hline \multicolumn{3}{|l|}{ Neonatal } \\
\hline Assisted ventilation & $0.58(0.42$ to 0.80$)$ & 1.63 (1.38 to 1.92$)$ \\
\hline Assisted ventilation excluding CPAP & $0.97(0.56$ to 1.69$)$ & $2.30(1.64$ to 3.22$)$ \\
\hline Seizures & $1.58(0.65$ to 3.84$)$ & 2.61 (1.19 to 5.72$)$ \\
\hline Respiratory distress syndrome & $0.60(0.53$ to 0.70$)$ & $0.82(0.72$ to 0.93$)$ \\
\hline Mortality and morbidity & $0.64(0.47$ to 0.86$)$ & 1.64 (1.39 to 1.93$)$ \\
\hline Restricted mortality and morbidity & $1.10(0.69$ to 1.76$)$ & $2.26(1.65$ to 3.10$)$ \\
\hline \multicolumn{3}{|l|}{ Failed VBAC } \\
\hline \multicolumn{3}{|l|}{ Maternal } \\
\hline Uterine rupture & $12.4(8.72$ to 17.7$)$ & 10.3 (7.78 to 13.6$)$ \\
\hline Uterine rupture not including dehiscence & $12.9(6.81$ to 24.4$)$ & 17.0 (9.69 to 29.7$)$ \\
\hline Severe morbidity & 2.67 (1.92 to 3.73$)$ & 2.69 (2.22 to 3.25$)$ \\
\hline \multicolumn{3}{|l|}{ Neonatal } \\
\hline Assisted ventilation & $1.22(0.96$ to 1.55$)$ & 2.53 (2.19 to 2.93 ) \\
\hline Assisted ventilation excluding CPAP & 1.84 (1.19 to 2.86$)$ & 3.93 (2.94 to 5.24$)$ \\
\hline Seizures & $1.66(0.72$ to 3.82$)$ & 3.22 ( 1.55 to 6.70$)$ \\
\hline Respiratory distress syndrome & 1.01 (0.90 to 1.13$)$ & 1.34 (1.20 to 1.49$)$ \\
\hline Mortality and morbidity & $1.22(0.97$ to 1.54$)$ & 2.50 (2.17 to 2.89$)$ \\
\hline Restricted mortality and morbidity & $1.73(1.17$ to 2.57$)$ & $3.67(2.79$ to 4.83$)$ \\
\hline \multicolumn{3}{|c|}{$\begin{array}{l}\text { Note: } \mathrm{Cl}=\text { confidence interval, } \mathrm{CPAP}=\text { continuous positive airway pressure, } \mathrm{RR}=\text { rate ratio, } \mathrm{VBAC}=\text { vaginal birth after cesarean. } \\
\text { *Our study contrasted women with an attempted vaginal birth after cesarean delivery compared with elective cesarean delivery among } \\
\text { women with a single prior pregnancy that resulted in a cesarean (reference group), who subsequently delivered a singleton at } 37 \text { to } \\
43 \text { weeks gestation in the current pregnancy in Canada (excluding Quebec) from } 2003 \text { to } 2005 \text { ( } n=38752 \text { for maternal outcomes; } n=36684 \\
\text { for neonatal outcomes) and from } 2012 \text { to } 2014 \text { ( } n=55246 \text { for maternal outcomes; } n=51991 \text { for neonatal outcomes). } \\
\text { tText in boldface type indicates a statistically significant temporal change in the adjusted RR ( } p<0.05 \text { ). } \\
\text { fLogistic models for maternal and neonatal outcomes included maternal age, diabetes mellitus, hypertension and labour induction. }\end{array}$} \\
\hline
\end{tabular}


position about the need for specialized services: in 2005, the Society of Obstetricians and Gynaecologists of Canada recommended that vaginal birth after cesarean deliveries be done in hospitals where a timely cesarean delivery was possible. ${ }^{30}$

Evidence related to attempted vaginal birth after cesarean delivery and the changes to the guidelines mentioned previously likely explains the finding of no association between attempted vaginal birth after cesarean delivery and severe neonatal morbidity and mortality in 2003-2005. A seminal study showing a near 2-fold increase in major maternal complications after a trial of labour was published in 1996, ${ }^{1}$ another study showing an 11-fold increase in perinatal death was published in $2002,{ }^{23}$ and a third study showing higher rates of maternal and infant complications was published in $2004 .{ }^{24}$ The climate of concern created by these studies likely affected the selection of candidates and labour management for attempted vaginal birth after cesarean delivery and ensured better perinatal outcomes during 2003-2005. The increase in the adverse effects for attempted vaginal birth after cesarean delivery more recently may indicate a less rigorous approach to selection of candidates and management of attempted vaginal birth after cesarean delivery. A reduction in the availability of obstetricians with expertise in vaginal birth after cesarean delivery and temporal changes in maternal characteristics are other possibilities.

The evaluation and interpretation of risks associated with attempted vaginal birth after cesarean delivery presents a challenge because risk perspectives vary widely. Both the relative increase in rates of severe maternal and neonatal morbidity and mortality after attempted vaginal birth after cesarean delivery compared with elective repeat cesarean delivery and the absolute difference in these rates need to be weighed carefully before a decision is made about whether the excess risks are acceptable or high. In additional, women planning large families need to be cognizant of the risks of morbid placentation in subsequent pregnancies, because such risks increase with repeated cesarean deliveries. ${ }^{9}$ These inputs into decision-making may also be affected by desire for vaginal birth, the severity of the outcomes in question and other personal valuations. Health care providers need to help women to contextualize risks better so that they are able to make informed and personalized decisions.

\section{Limitations}

The limitations of our study include reliance on data from a large perinatal database, which may contain some transcription and other errors. Although codes for major diagnoses and procedures in our data source have been validated and found to be accurate, misclassification of some women scheduled for elective repeat cesarean delivery is possible. However, this would have served to minimize differences between elective repeat cesarean delivery and attempted vaginal birth after cesarean delivery, and sensitivity analyses restricted to women at 40 weeks or more gestation support this assumption.

\section{Conclusion}

Attempted vaginal birth after cesarean delivery is associated with low absolute rates of severe maternal and infant morbidity and mortality, although relative rates of such adverse outcomes are higher than for elective repeat cesarean delivery. Temporal trends in the effects of attempted vaginal birth after cesarean delivery on serious neonatal morbidity and mortality have shown a concerning increase in recent years, and further study is required to identify the cause of this unexpected development. Attempts at ensuring the safety of attempted vaginal birth after cesarean delivery must continue to focus on appropriate selection of candidates and careful monitoring of labour and delivery among women with a previous cesarean delivery.

\section{References}

1. McMahon MJ, Luther ER, Bowes WA Jr, et al. Comparison of a trial of labour with an elective second cesarean section. N Engl J Med 1996;335:689-95.

2. Sachs BP, Kobelin C, Castro MA, et al. The risk of lowering the cesarean-delivery rate. N Engl J Med 1999;340:54-7.

3. Smith GC, Pell JP, Cameron AD, et al. Risk of perinatal death associated with labour after previous cesarean delivery in uncomplicated term pregnancies. JAMA 2002;287:2684-90.

4. Landon MB, Hauth JC, Leveno KJ, et al. Maternal and perinatal outcomes associated with a trial of labour after prior cesarean delivery. N Engl J Med 2004; 351:2581-9.

5. Smith GC, Pell JP, Pasupathy D, et al. Factors predisposing to perinatal death related to uterine rupture during attempted vaginal birth after cesarean section: retrospective cohort study. BMJ 2004;329:375.

6. Brennan DJ, Robson MS, Murphy M, et al. Comparative analysis of international cesarean delivery rates using 10-group classification identifies significant variation in spontaneous labour. Am J Obstet Gynecol 2009;201:308.e1-8.

7. Guise JM, Eden K, Emeis C, et al. Vaginal birth after cesarean: new insights. Evid Rep Technol Assess (Full Rep) 2010;191:1-397.

8. Dodd JM, Crowther CA, Grivell RM, et al. Elective repeat cesarean section versus induction of labour for women with a previous cesarean birth. Cochrane Database Syst Rev 2014;(12):CD004906.

9. National Institutes of Health Consensus Development Conference Panel. National Institutes of Health Consensus Development conference statement: vaginal birth after cesarean: new insights. March 8-10, 2010. Obstet Gynecol 2010;115:1279-95.

10. Guise JM, Denman MA, Emeis C, et al. Vaginal birth after cesarean: new insights on maternal and neonatal outcomes. Obstet Gynecol 2010;115:1267-78.

11. Allen VM, O'Connell CM, Baskett TF. Maternal morbidity associated with cesarean delivery without labour compared with induction of labour at term. Obstet Gynecol 2006;108:286-94

12. Canadian Perinatal Health Report, 2000. Ottawa: Health Canada; 2000.

13. Indications for cesarean section: final statement of the panel of the National Consensus Conference on Aspects of Cesarean Birth. CMAJ 1986;134:1348-52.

14. Vaginal birth after cesarean section. SOGC Bulletin 1986; vol 8; no 1.

15. Consensus Development Conference of Cesarean Childbirth, September 1980. NIH pub no. 82-2067, Bethesda (MD): National Institutes of Health; 1981.

16. American College of Obstetricians and Gynecologists. Guidelines for vaginal delivery after a previous cesarean birth. Committee Opinion No. 64, October 1988.

17. American College of Obstetricians and Gynecologists. Vaginal delivery after previous cesarean birth. Committee Opinion No. 143, October 1994.

18. American College of Obstetricians and Gynecologists. Vaginal birth after previous cesarean delivery. Practice Bulletin No. 2, October 1998.

19. American College of Obstetricians and Gynecologists. Vaginal birth after previous cesarean delivery. Practice Bulletin No. 5, July 1999.

20. American College of Obstetricians and Gynecologists. Vaginal birth after previous cesarean delivery. Practice Bulletin No. 115, Reaffirmed 2013.

21. User guide to the 2014 natality public use file. Hyattsville (MD): Centers for Disease Control and Prevention National Center for Health Statistics; 2014. Available: www.cdc.gov/nchs/data_access/Vitalstatsonline.htm (accessed 2017 Nov. 20). 
22. Perinatal health report: deliveries in British Columbia 2014/15. Vancouver: Perinatal Services BC; 2016. Available: www.perinatalservicesbc.ca/Documents/ Data-Surveillance/Reports/PHR/PHR_BC_2014_15.pdf (accessed 2017 Nov 20).

23. Wen SW, Liu S, Marcoux S, et al. Uses and limitations of routine hospital admission/ separation records for perinatal surveillance. Chronic Dis Can 1997;18:113-9.

24. Joseph KS, Fahey J. Validation of perinatal data in the Discharge Abstract Database of the Canadian Institute for Health Information. Chronic Dis Can 2009;29:96-100.

25. Frosst G, Hutcheon J, Joseph KS, et al. Validating the British Columbia Perinatal Data Registry: a chart re-abstraction study. BMC Pregnancy Childbirth 2015;15:123.

26. Joseph KS, Liu S, Rouleau J, et al.; Maternal Health Study Group of the Canadian Perinatal Surveillance System. Severe maternal morbidity in Canada, 2003 to 2007: Surveillance using routine hospitalization data and ICD-10CA codes. J Obstet Gynaecol Can 2010;32:837-46.
27. Liu S, Joseph KS, Bartholomew S, et al.; Maternal Health Study Group of the Canadian Perinatal Surveillance. Temporal trends and regional variations in severe maternal morbidity in Canada, 2003 to 2007. J Obstet Gynaecol Can 2010;32:847-55

28. Lyons J, Pressey T, Bartholemew S, et al.; for the Canadian Perinatal Surveillance System (Public Health Agency of Canada). Delivery of breech presentation at term gestation in Canada, 2003 to 2011. Obstet Gynecol 2015;125: 1153-61.

29. Muraca GM, Sabr Y, Lisonkova S, et al. Perinatal and maternal morbidity and mortality associated with midpelvic operative vaginal delivery and cesarean delivery: a population-based retrospective cohort study. CMAJ 2017;189:E764-72.

30. Martel MJ, MacKinnon CJ; Clinical Practice Obstetrics Committee, Society of Obstetricians and Gynaecologists of Canada. Guidelines for vaginal birth after previous Cesarean birth. J Obstet Gynaecol Can 2005;27:164-88.

\section{Competing interests: None declared.}

This article has been peer reviewed.

Affiliations: Department of Obstetrics and Gynecology (Young), Faculty of Medicine and Dentistry, University of Alberta, Edmonton, Alta; Maternal, Child and Youth Health Division (Liu), Centre for Surveillance and Applied Research, Public Health Agency of Canada, Ottawa, Ont.; Department of Obstetrics and Gynaecology (Muraca, Sabr, Pressey, Liston and Joseph), Faculty of Medicine; School of Population and Public Health (Muraca, Joseph), University of British Columbia; Children and Women's Health Centre of British Columbia (Muraca, Sabr, Pressey, Liston and Joseph), Vancouver, BC;
Department of Obstetrics and Gynaecology, College of Medicine, King Saud University, Riyadh, Saudi Arabia (Sabr).

Contributors: Carmen Young proposed the study and wrote the first draft of the manuscript. Carmen Young, K.S. Joseph and Shiliang Liu carried out the analysis. All of the authors reviewed the preliminary and final analyses, reviewed the manuscript critically for important intellectual content, gave final approval of the version to be published and agreed to be accountable for all aspects of the work in ensuring that questions related to the accuracy or integrity of any part of the work are appropriately investigated and resolved.
Funding: Giulia Muraca received a Vanier Canada Graduate Scholarship and is supported by a Canadian Institutes of Health Research (CIHR) grant to study severe maternal morbidity (MAH-15445). K.S. Joseph is supported by the British Columbia Children's Hospital Research Institute and holds a CIHR Chair in maternal, fetal, and infant health services research (APR-126338). This study was conducted under the auspices of the Canadian Perinatal Surveillance System.

Accepted: Feb. 7, 2018

Correspondence to: Carmen Young, cbyoung@ualberta.ca 